\title{
Using quantitative and qualitative unit profiling for identifying the contribution of library resources to teaching quality
}

\author{
Stuart Palmer
}

\begin{abstract}
This paper presents the development and application of a new methodology incorporating both quantitative and qualitative profiling to help discern the characteristics of units of study that are the differentiators of student ratings of library resource quality. From the sub-set of those units with an 'unremarkable' rating for teaching quality, those units with the 'extreme' library resource quality ratings were selected for investigation. Examination of the handbook descriptions for those units suggests that units of study which explicitly incorporate student interaction with the wider literature and other information resources beyond those provided within the unit environment may lead students to engage with the library in deeper ways that highlight the value of library resources, and hence lead to higher mean ratings of library resource quality. This finding suggests potential areas for intervention to enhance student perceptions of the quality of library resources.
\end{abstract}

\section{Introduction}

This paper documents an investigation to identify the characteristics of units of study at Deakin University that differentially contribute to students' ratings of library resource quality. Knowing those characteristics would suggest potential areas for intervention to enhance student perceptions of the quality of library resources. Intentionally drawing on both quantitative and qualitative data sources and analysis methods, this investigation has the aim of achieving insights not available via either method alone.

Internationally, university libraries have embraced quality evaluation to a significant degree. Large surveys of library user service quality perception are

\section{Author}

Stuart Palmer is Associate Professor in the Institute of Teaching and Learning at Deakin University, Australia. A Chartered Professional Engineer, he lectured in the School of Engineering for 12 years. He now focuses on academic development and institutional research initiatives.

Email: spalm@deakin.edu.au 
frequently employed. Internationally the LibQUAL+ survey run by the US Association of Research Libraries (ARL) is commonly used (Cook et al., 2001; Thompson, Cook \& Kyrillidou, 2006; Walters, 2003). In the UK the Society of College, National and University Libraries (SCONUL) satisfaction survey has been frequently used (Crawford, 2003). In Australasia the Council of Australian University Librarians sponsors the use of the Insync survey (Horn, Calvert \& Ferguson, 2009; Zauha \& Potter, 2009). These surveys have their foundation in the generic SERVQUAL service quality framework (Parasuraman, Zeithaml \& Berry, 1988). The SERVQUAL methodology is based on identified domains of service quality, and within these domains users provide ratings of both their expectations and their actual experiences. The difference between the ratings of expectation and experience is referred to as the gap or 'disconfirmation'. Where the rating of actual experience is significantly lower than the expectation rating, this is suggested to indicate an area for action to improve service performance. In addition, absolute performance ratings can be used as a point of comparison to benchmark against other libraries.

Although SERVQUAL-type service quality surveys are widely used, the underpinning methodology has been criticised on many bases, including theoretical, methodological and psychometrical (Brown, Churchill Jr \& Peter, 1993; Buttle, 1996; Chen, Gupta \& Rom, 1994). The application of the SERVQUAL framework to measure service quality in higher education has been found to have limitations, both generally (Li \& Kaye, 1998), and specifically in the context of academic libraries (Nitecki, 1996). Being derived from the SERVQUAL framework, the LibQUAL+ survey (and its kin) inherits many of the same theoretical criticisms (Jayasundara, 2011), and also has others (Walters, 2003). While the ability to benchmark between surveying organisations is desirable, an investigation by SCONUL found that the relationship between user satisfaction levels and the specific services offered by an individual library is complex, making inter-institutional comparisons of service quality survey data problematic for all but the overall satisfaction ratings (West, 2001). The comparative ranking of performance results from service quality surveys, while potentially useful for inter-institutional benchmarking, does not actually guarantee anything about the absolute level of service quality - i.e., the top ranked performance in a comparison set may still be deficient in an absolute sense (Mundt, 2003).

In Australia, it is a requirement that universities participate in the nationally administered student Course Experience Questionnaire (CEQ). The CEQ is run annually by Graduate Careers Australia, and is administered to graduates approximately four months after completing their studies. The CEQ is one of the most strongly validated national student evaluation of teaching (SET) instruments internationally (Barrie \& Ginns, 2007). All universities must report rating data for two compulsory scales ("good teaching" and "generic skills"), as well as an "overall satisfaction item". Universities may also include a range of optional scales in the CEQ survey that they send to their graduates. The optional student support scale (SSS) of the CEQ was included by 20 institutions in 2009, attracting nearly 20,000 responses. The SSS includes item SSS34 ("The library services were readily accessible"). Figure 1 shows that SSS34 has historically been the 
highest rating (percentage agreement) item in the SSS; in fact SSS34 has historically been one of the highest rating items in the entire CEQ. The optional Learning Resources Scale (LRS) of the CEQ was included by 14 institutions in 2009, attracting nearly 11,200 responses. The LRS includes item LRS12 ("The library resources were appropriate for my needs"). In contrast, Figure 2 shows that LRS12 has, in recent years, been one of lowest rating items in the LRS, and consistently significantly lower rating than SSS34 in absolute terms.

SSS34 - The library services were readily accessible

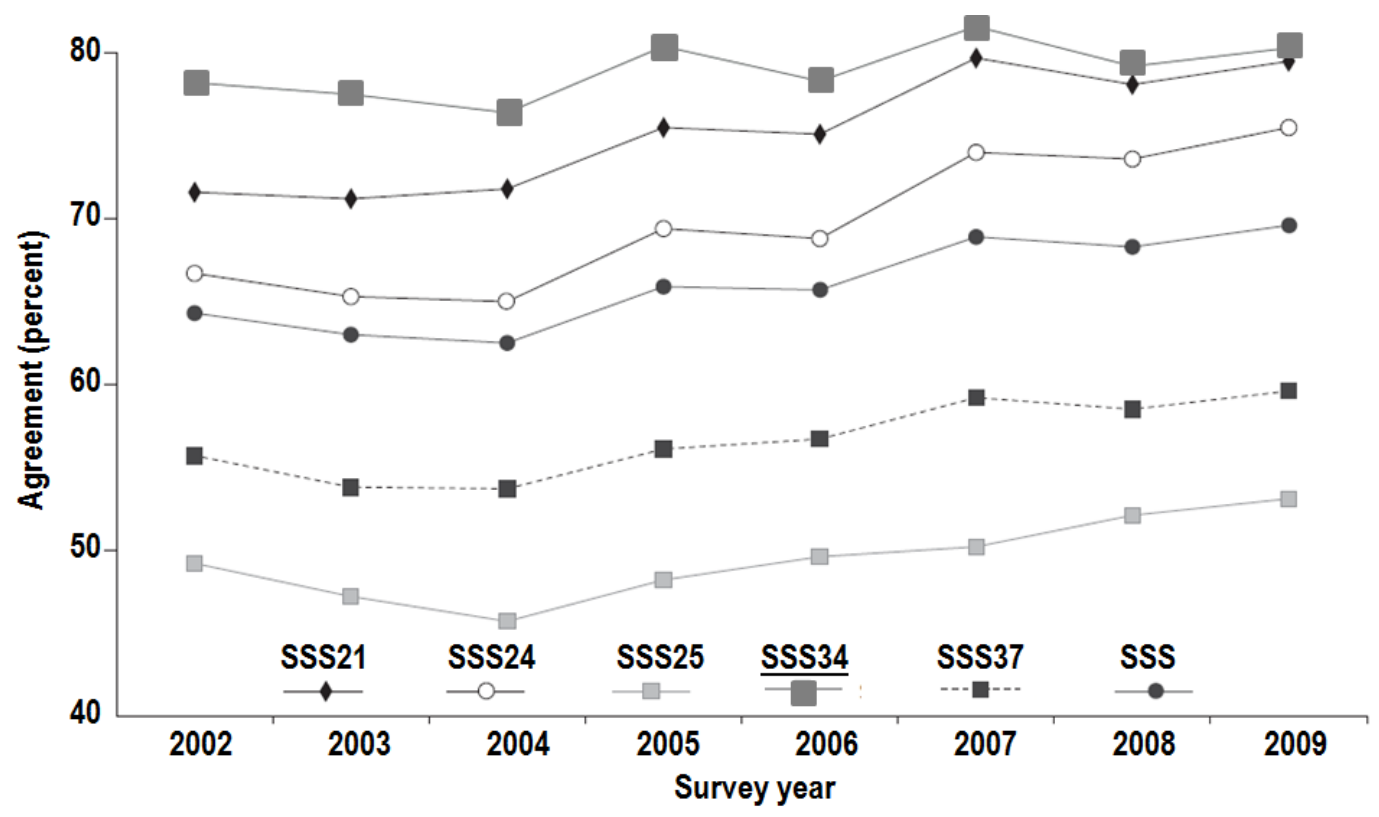

Figure 1: CEQ Student Support Scale percentage agreement time series. Source: Figure 21 (Graduate Careers Australia, 2010, 32) reproduced with permission. 


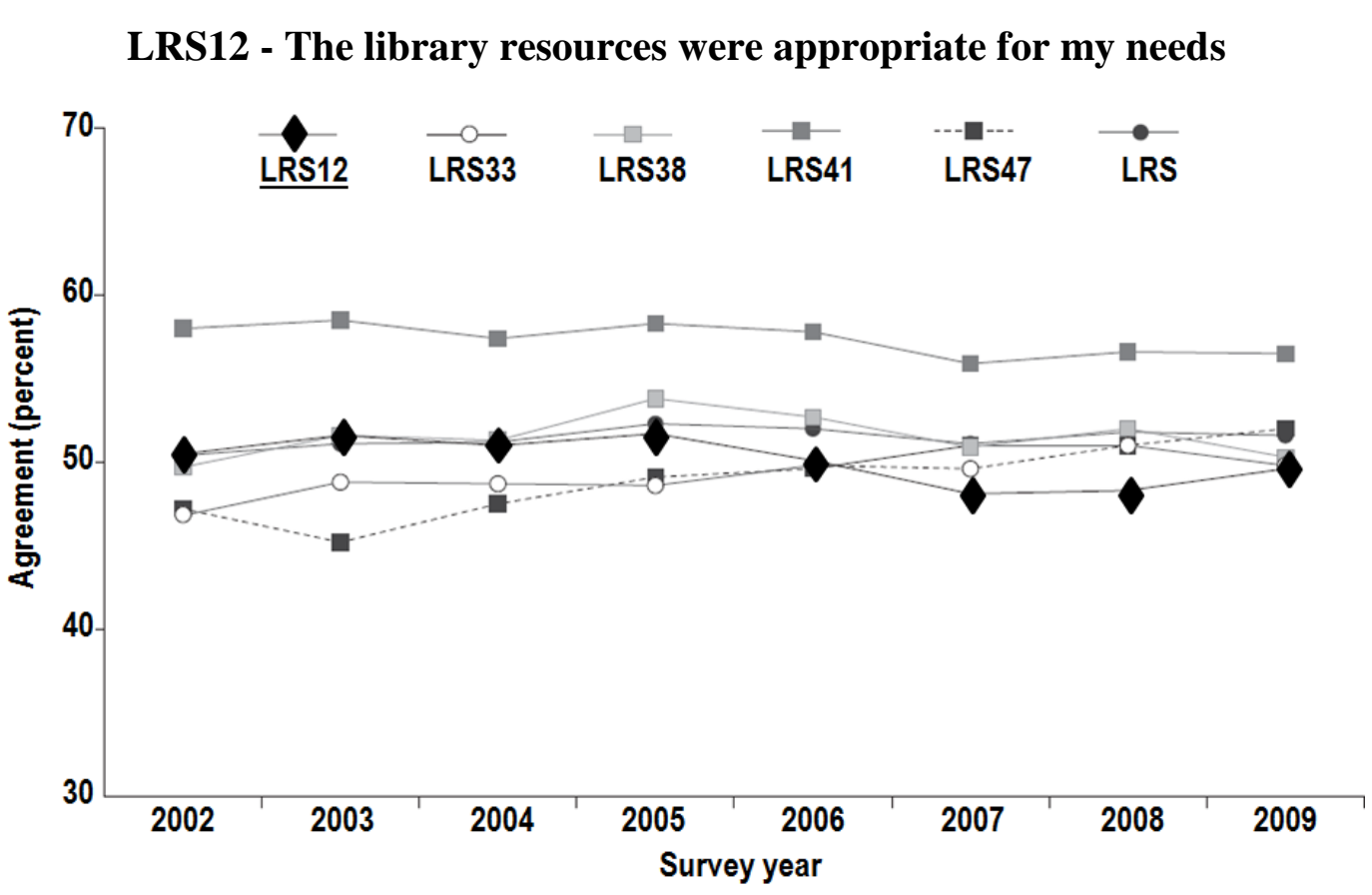

Figure 2: CEQ Learning Resources Scale percentage agreement time series. Source: Figure 23 (Graduate Careers Australia, 2010, 33) reproduced with permission.

So, at a national level in Australia, there is evidence that while university library service quality is rated highly, library resource quality is rated comparatively lowly. In the case of Deakin University, a 2010 overall satisfaction rating in the top quartile of the Australasian Insync survey (Deakin University Library, 2010) suggests a high general level user satisfaction with the Deakin University Library. Another source of library evaluation data at Deakin University is the student evaluation of teaching and units (SETU) survey. In its current form, the SETU instrument consists of ten core items:

1. This unit was well taught.

2. The course materials in this unit were of high quality.

3. The workload in this unit was manageable.

4. Requirements for completing the assessment tasks in this unit were clear.

5. The teaching staff gave me helpful feedback.

6. The library resources met my needs for this unit.

7. I would recommend this unit to other students.

8. The technologies used to deliver the online content in this unit performed satisfactorily.

9. The on-line teaching and resources in this unit enhanced my learning experience.

10. This unit challenged me to learn. 
SETU respondents rate each core item on a five point scale (1=strongly disagree; $2=$ disagree; $3=$ neutral; $4=$ agree; $5=$ strongly agree) with a 'not applicable' option included.

Following the completion of the SETU survey period and collation of results, SETU data are reported via a public website (Deakin University, 2011); anyone with an interest can query the results for the ten core SETU items. The mean ratings for SETU items 1, 7 and 9 take on a particular significance, as these items are reported to the University Council as overall teaching quality indicators for a unit of study. Figure 3 summarises seven years of recent SETU mean ratings data consolidated at the whole university level. It shows that item 6 ("The library resources met my needs for this unit") is amongst the lowest rating items historically. So, as with the CEQ nationally in Australia, at Deakin University there is evidence from SET data that high ratings of library service quality do not automatically coincide with high ratings of library resource quality.

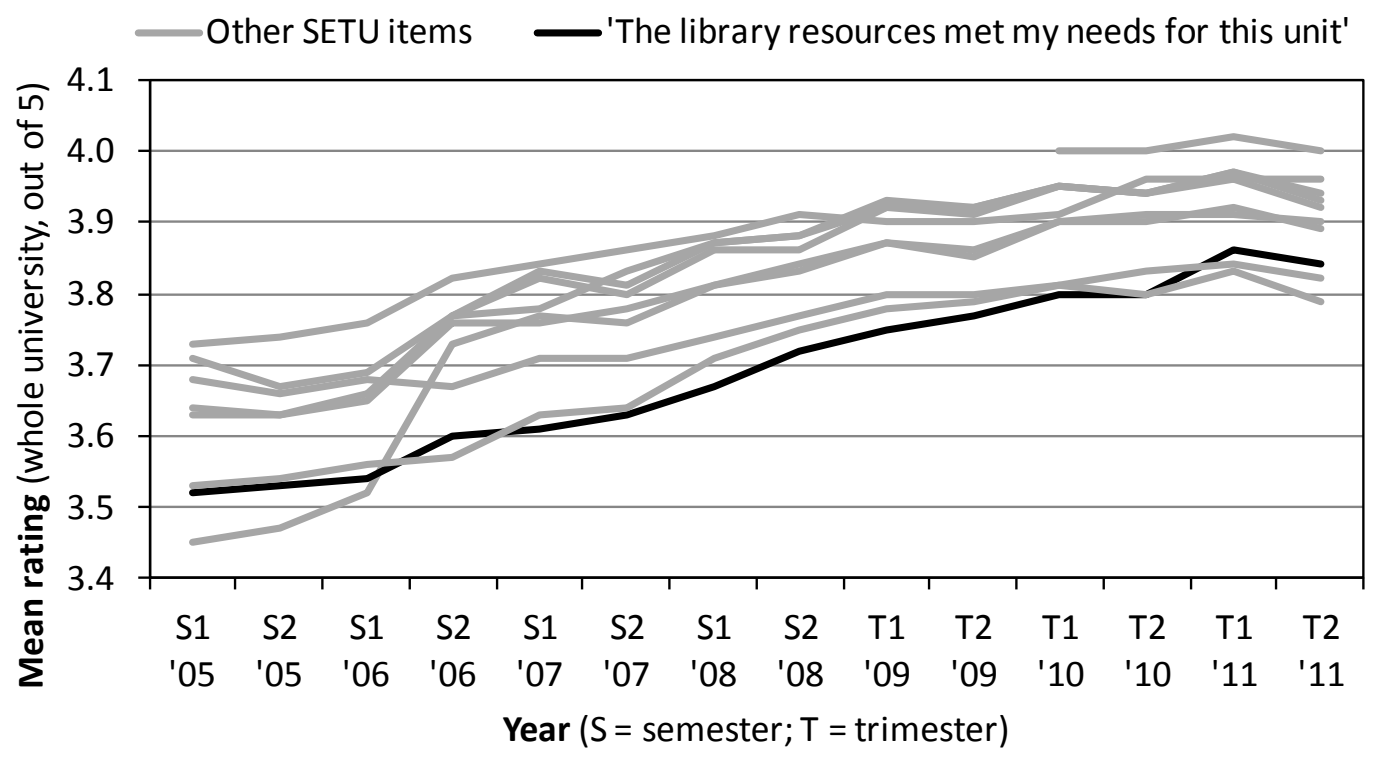

Figure 3: Comparison of SETU item 6 (library item) with all other SETU items. Source: data from (Deakin University, 2011).

There is no doubt that the library plays an important part in the student experience of university life. Theoretical constructs of university quality derived from reviews of the literature often explicitly include satisfaction with library service (Arambewela \& Hall, 2006; Gruber \& Voss, 2010). While service quality measurements are always likely to be important for a library, libraries have moved beyond being solely service and support providers, and now often play a direct role in student learning (Owusu-Ansah, 2004). In an investigation of the factors contributing to user satisfaction with an academic library website, perceptions of resource quality were found to be the most important factor (Joo, 2010). 
If SET data are suggesting a disparity in ratings between library service quality and library resource quality, then perhaps SET data can also provide insights into what contributes to the perception of library resource quality, and hence identify leverage points for quality improvement interventions. The use of data relating to the library from existing SET instruments is not a new idea - examples can be found in the literature (Brookes, 2003; Symons, 2004). While the numerical results from user rating surveys may provide valuable quantitative evaluation data, there is a recognition that a more holistic assessment of library service and resource quality can be obtained through the synthesis of multiple data sources, including qualitative data sources (Griffiths, 2008). Based on work by the UK Online Centres, one qualitative evaluation method suggested for libraries as a means to supplement quantitative measures, and to help translate "faceless data" into outcomes that are more tangible, is "customer profiling" (Rooney-Browne, 2011).

In the analysis presented here, this approach is adapted as the 'profiling' of individual units of study to provide enhanced insights into quantitative unit SET data through the consideration of related qualitative data. Initially, any other SETU items having an association with SETU item 6 (relating to library resources) were identified using Deakin University SETU data and standard statistical methods. A new method to identify a small sub-set of all units encapsulating the extreme (highest and lowest) ratings of library resource quality relative to teaching quality was used to select target units for closer examination. The unit handbook descriptions for these units were then analysed to identify common characteristics that might differentiate between units obtaining high and low mean ratings for SETU item 6.

\section{Methodology}

Mean ratings for the ten core SETU items for all units of study reporting data via the Deakin University SETU web site were collected for the whole year period of mid-2009 to mid-2010. The SETU data were analysed to identify significant correlations between the mean rating for item 6 (relating to the library) and other SETU item mean ratings. The aim here was to identify any other SETU item(s) having a particular association with item 6 , and hence suggesting potential areas for intervention to enhance student perceptions of the quality of library resources.

To select a small number of units of study for closer investigation, the following method was used to identify units with characteristics most likely to qualitatively highlight the differences between higher and lower mean ratings for SETU item 6.

- the mean of all mean ratings for SETU item 1 was determined;

- a small range on either side of this 'mean of means' was selected;

- all units with a SETU item 1 mean rating in this range were considered; and

- the units within this range with the highest and lowest mean rating for SETU item 6 were identified for further investigation.

The rationale for, and operation of, this unit selection procedure will be presented in more detail in the following section. For the units identified for investigation, 
their description was extracted from the Deakin University online handbook (Deakin University, 2010). The handbook is publicly available online, and the description for each unit includes a summary of the unit content and assessment. These handbook descriptions were analysed to identify any characteristics of the profiled units that might distinguish between units with high and low mean ratings for SETU item 6. Apart from Figures 1 and 2, which are slightly modified versions from the source cited, all other figures were produced using Microsoft Excel.

\section{Results and Discussion}

The data extracted from the SETU reporting web site and used in the analysis here included mean rating sets for 1432 units of study, and represented 74498 sets of SETU ratings, 188391 individual student enrolments and 58.5 percent of all units listed in the Deakin University online handbook (Deakin University, 2010) for the period under consideration. A comparison of the correlation between unit-level mean ratings for SETU item 6 and all other SETU items is given in Table 1. Correlation is given as Pearson linear correlation coefficient, and the computed statistical significance is also provided.

\begin{tabular}{|c|c|c|c|c|c|c|c|c|}
\hline Item & Correl. & Signif. & Item & Correl. & Signif. & Item & Correl. & Signif. \\
\hline $\mathbf{1}$ & $r=0.564$ & $p<4 \times 10^{-121}$ & $\mathbf{2}$ & $r=0.589$ & $p<2 \times 10^{-134}$ & $\mathbf{3}$ & $r=0.438$ & $p<4 \times 10^{-68}$ \\
$\mathbf{4}$ & $r=0.511$ & $p<5 \times 10^{-96}$ & $\mathbf{5}$ & $r=0.547$ & $p<2 \times 10^{-112}$ & $\mathbf{7}$ & $r=0.585$ & $p<3 \times 10^{-132}$ \\
$\mathbf{8}$ & $r=0.560$ & $p<4 \times 10^{-119}$ & $\mathbf{9}$ & $r=0.589$ & $p<3 \times 10^{-134}$ & $\mathbf{1 0}$ & $r=0.513$ & $p<2 \times 10^{-46}$ \\
\hline
\end{tabular}

Table 1: Correlation between SETU item 6 rating and all other SETU items.

It is observed that the mean ratings of all other SETU items are significantly and strongly positively correlated with item 6 . This association between SETU item 6 and other items can be visualised by using SETU item 1 ('This unit was well taught') as an example, and plotting all mean unit SETU ratings pairs for item 1 and item 6. This visualisation is shown in the scatter plot presented in Figure 4. Note that each point on Figure 4 may represent more than one mean ratings pair. 


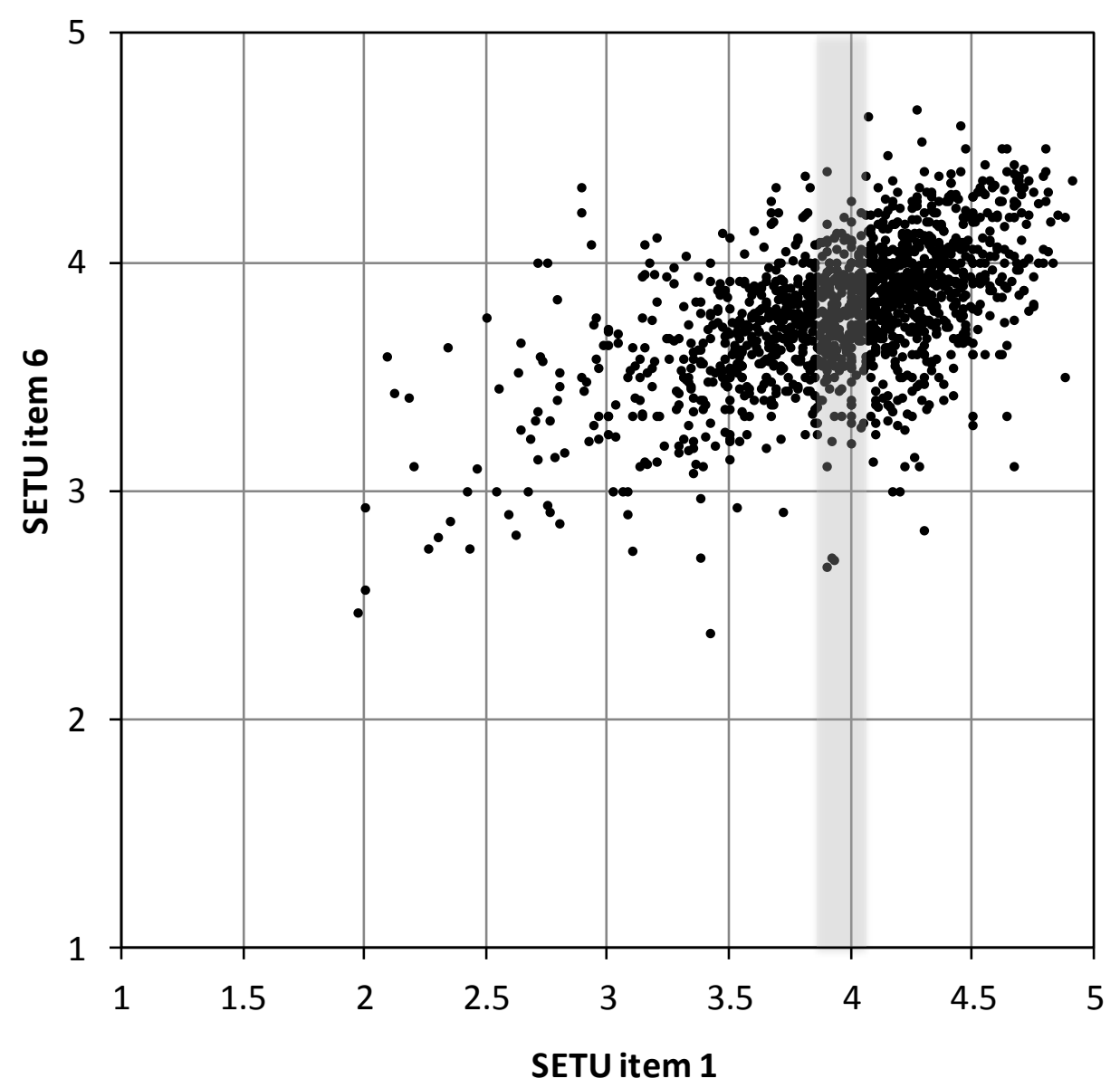

Figure 4: Scatter plot of mean unit SETU ratings pairs for item 1 and item 6.

The strong linear relationship between SETU items 1 and $6(r=0.564)$ is readily apparent in Figure 4 - the points in the scatter plot cluster around a diagonal line. The practical outcome of this association is that units that rate highly on "good teaching" also generally rate highly on "quality of library resources", and vice versa. It is not clear what the source(s) of this association is/are. It may be a manifestation of the halo effect, where one unit trait (perception of teaching quality) influences students' assessment of other unit traits - in this case, perception of quality of library resources. Significant halo effects on students' rating of the relationship between perceived learning outcomes and study experiences, including library-related experiences have been observed (Pike, 1999). Another possible contribution to the observed association, and not mutually exclusive of a halo effect, is that highly rated teachers are likely to have carefully considered and planned other aspects of the unit learning environment experienced by students, including meaningful integration with university academic support services - i.e., good teaching and learning may naturally include the library.

The presence of a halo error will tend to obscure the nature of any relationship between items being rated. Even in the absence of a halo error, the strong observed correlation between SETU items 1 and 6 suggests that, to improve the 
rating for item 6, the Deakin University Library would do 'best' to ensure that all teaching staff are good teachers! In addition, based on the other observed SETU item correlations with item 6, the Library should also ensure that all unit materials are of high quality, that all unit workloads are manageable, that all units have clear assessment guidelines, etc. This result means there is limited utility in the summary descriptive SETU statistics in providing guidance for the Library on specific actions that might be taken to improve the overall mean rating of item 6 . In the case of the library SETU item, a previous investigation at Deakin University concluded, “... it appears that little additional information is gained from SETU Q6 that would assist the Library in its quality improvement." (Deakin University, 2009, 13)

If the consolidated, all-in SETU data suggest little more than units with highly rated teachers also achieve high ratings for library resource quality, and vice versa, then perhaps the profiling of selected individual units that depart from this typical relationship may be more revealing of those unit characteristics that genuinely differentially contribute to student ratings of library resource quality. In turn, these characteristics may assist in identifying key points of leverage for the library to target quality improvement interventions. So, rather than simply examining those units that rate highly (and lowly) on SETU item 6 and/or item 1 per se, instead, those units that score around the overall mean rating for SETU item 1 are selected, and then the 'outliers' on SETU item 6 rating amongst them are targeted for closer investigation. The rationale here is that units with an 'unremarkable' rating for teaching aspects in combination with 'extreme' ratings for library resource aspects should help disambiguate the association between SETU items 1 and 6, and highlight those unit characteristics that contribute to student ratings of library resource quality.

The observed distribution of unit mean ratings for SETU item 1 was approximately normal (Kurtosis 1.51; Skewness -0.97), with a mean value of 3.96. If a range of SETU item 1 mean ratings of plus and minus 0.1 around 3.96 is considered, this incorporates 267 units of study, or 18.65 percent of the 1432 units included in this project. This range is indicated by the grey vertical shading in Figure 4, and Figure 5 presents an expanded scatter plot showing mean rating pairs of SETU item 1 and 6 for all units that fall in this selected range. The size of the data point markers at mean SETU rating pair points in Figure 5 are proportional to the number of units of study reporting that mean SETU rating pair. Note that the SETU reporting system presents mean item rating data with two decimal places of precision, hence the appearance of data point markers in Figure 5 being confined to distinct values on a grid, with this being most evident on the horizontal axis which is most highly expanded for presentation. 


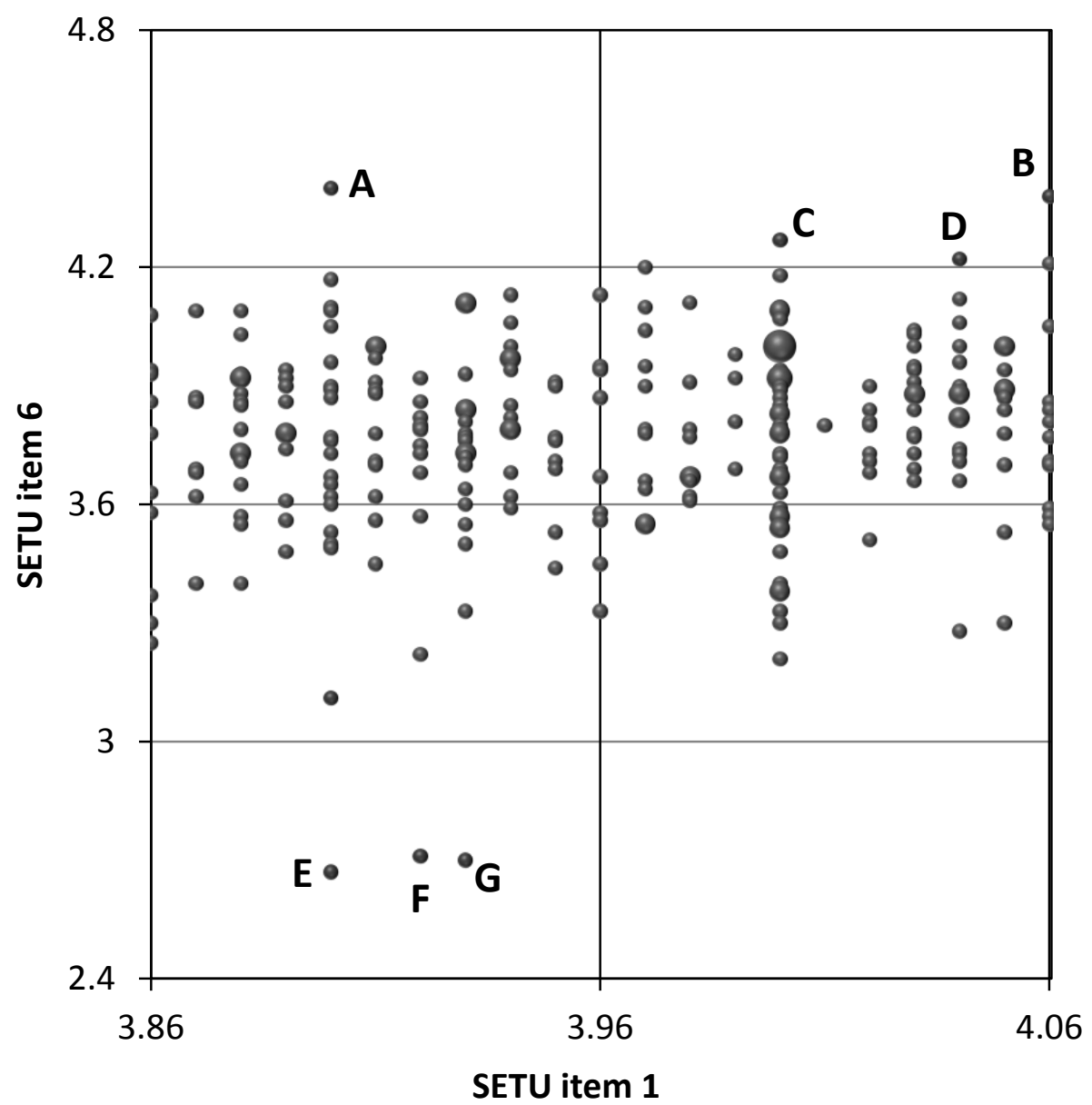

Figure 5: Expansion of Figure 4 around the overall mean rating for SETU item 1.

From those units of study contained in Figure 5, the four data points with highest mean ratings for SETU item 6 were identified (points A-D in Figure 5), along with the three with the lowest mean ratings for SETU item 6 (points E-G). All of the seven data points selected for investigation represent single unique units of study. It is acknowledged that the 'plus and minus 0.1 around 3.96' range chosen is somewhat arbitrary, and a different range would potentially result in a different selection of units for investigation. Likewise, while points E-G form a group with means ratings for SETU item 6 that are clearly lower than all others, the selection of the four units with the highest mean ratings is again somewhat arbitrary, as there is no group of units with mean ratings that are clearly higher than all others. Finally, the data points plotted in Figures 4 and 5 represent mean unit ratings derived from unit SETU response rates of less than 100 percent. Because of this, they represent statistical estimates of the true mean ratings, and inherently contain a degree of uncertainty, which in this case is difficult to quantify, as only summary statistical data are available via the SETU system. With these limitations identified, profiling of these selected units was then considered. Table 2 presents the handbook entries for the units A-D. Table 3 presents the handbook entries for units E-G. 


\section{Unit A - Postgraduate level unit in Master of literature program}

Content - Students will study the picture-book from an aesthetic and semiotic perspective, considering the ways in which visual and verbal text interact to produce various kinds of meaning. Nineteenth and early twentieth-century illustrated books are discussed in relation to their artistic and literary contexts, leading to a focus on recent and contemporary picture books. Students will be given the option of writing a picture-book text and will receive instruction in this form of writing.

Assessment - Essay 2000 words 30\%, reading journal or essay 1500 words 30\%, picture-book text or essay 2000 words $40 \%$

\section{Unit B - Third-year unit in Bachelor of commerce program}

Content - As a requirement of International Education Standard 4 released by the International Federation of Accountants, the unit develops students' appreciation of ethics and their ability to evaluate and apply ethical principles in the decisionmaking process in accounting and finance. Topics covered include: the nature of ethics; an ethics framework of relationships for financial services; ethical factors influencing the performance of financial services; ethical theories and principles applicable to finance professionals; ethical decision-making models; ethical issues and conflicts of interest in the financial services industry; professional codes and workplace ethics; corporate social responsibility; applying ethical decisions in case scenarios; and international business practices.

Assessment - Written assignment 11500 words 20\%, written assignment 22500 words $30 \%$, examination 2 hours $50 \%$

Unit C - Fourth-year maths elective unit in Bachelor of education program

Content - This unit will address both theoretical and practical aspects of mathematical problem solving. Participants will be expected to access some of the important print and on-line national and international literature in the area, interact with video showing problem solving in classrooms across a range of year levels, engage in the process of attempting to solve non-routine problems, as well as reflect on the strategies they used and the solution paths they followed. Emphasis will also be placed on classroom aspects of problem solving, including the need to actively involve students, the role of the teacher, evaluation and resources, including web-based resources for teachers and students. Participants will prepare, trial and critically evaluate problem-solving activities for use with primary or secondary school students.

Assessment - Two written assignments (40\% and 60\%) based on theoretical and practical aspects of problem solving, including participants' solutions to problems and a report on implementing problem-solving activities with students. Assessment will total 4000 words or equivalent.

Unit D - Honours year research methods unit in Health sciences program

Content - This honours unit will complement the work of research supervisors by teaching and developing selected skills which are important in research and 
advantageous in careers other than research. Topics to be addressed include effective written and verbal communication skills, the presentation and defence of a research proposal, the preparation of a written research proposal, and the writing of a literature review.

Assessment - Oral presentation 20\%, research proposal 20\%, literature review (6000 words) $60 \%$

Table 2: Handbook descriptions for profiled units with high library rating.

\section{Unit E - Third-year unit in Bachelor of construction management program}

Content - This unit builds on the fundamentals of project management to plan and manage a major facility event, such as organisational restructure or premises relocation. Issues of effective communication to building users and the sequencing of sub-events are explored via an authentic case study. Students form teams, assign tasks and develop plans for the successful implementation of the event and gain an understanding of the complexity of event management coordination. Methods for the evaluation of success are also discussed.

Assessment - Assignment (brief development) 25\%, assignment (project resourcing) $25 \%$, assignment (project plan) $25 \%$, oral presentation (event management) $25 \%$

\section{Unit F - Second-year Chinese language unit in Bachelor arts program}

Content - The unit aims at developing and refining students' communicative skills in and interactive use of Chinese achieved in [previous unit]. It will continue to focus on listening, speaking, reading and writing in the Chinese language.

Students will learn to use Chinese in everyday situations. Topics to be covered include meeting new friends, studying, shopping, going to the Post Office, seeing doctors, entertainment, social intercourse, etc. Students will also be introduced to background knowledge of the Chinese culture and society.

Assessment - Weekly written assignments $20 \%$, oral class presentation $20 \%$, oral examination $20 \%$, written examination $40 \%$.

\section{Unit G - Third-year unit in Bachelor of creative arts program}

Content - This unit is targeted to emerging freelance artists across the creative arts industry. It aims to develop knowledge of how to get projects developed and supported. It focuses on the artist's role and responsibility in a freelance environment. Topics include critical analysis of cultural policies and art practice; project management and working with others; career planning and goal setting; ethical and legal considerations for art practitioners; relationships of artists, administrators and audiences. The unit also looks at processes and strategies for developing funding, marketing and promotion; networking; grant applications; and resources for developing professional art projects.

Assessment - Seminar paper/participation equiv 500 words 20\%; Project application and oral pitch equiv 2500 words $50 \%$; In-class final exercise equiv 1000 words $30 \%$

Table 3: Handbook descriptions for profiled units with low library rating. 
Of the high rating unit group (A-D), three of the four (A, C and D) unit descriptions explicitly identify that students will engage with 'literature' of various forms - these references are underlined in Table 2. In these three units, students would presumably have to engage with the library and/or library-related resources in a context directly associated with their unit studies, and it would seem likely that this would make the relevance and value of such resources readily apparent. Such explicit references regarding literature are absent from all of the low rating unit group (E-G) unit descriptions.

The fourth of the high rating units (B) deals with the complex and contextdependent topic of ethical decision making. Additionally, half of the unit marks are allocated to in-semester assignment tasks, suggesting that they are significant elements in the unit. In 2009 and 2010 Deakin University participated in the Australasian Survey of Student Engagement (AUSSE) (Coates, 2010). In the AUSSE students provide generally quantitative ratings for a large number of items, including the item "Used library resources on campus or online". In a previous investigation, the Deakin University AUSSE data for 2009 and 2010 were analysed to identify significant correlations between the mean rating for the item relating to the library and the mean ratings for other AUSSE items (Palmer, 2012). Amongst a number of largely minor correlations, a single pair-wise correlation stood out, in both years, as having approximately twice the explanatory association with the AUSSE 'library' item than all others - that item was "Worked on an essay or assignment that required integrating ideas or information from various sources". This finding suggests that units of study that employ more sophisticated assessment regimes that require students to engage with multiple sources of information are more likely to lead students to interact with and value the library. This may be one mechanism contributing to the comparatively high rating of library resources in unit B.

If there is a common characteristic of the low rating unit group, it is perhaps that the unit descriptions identify these units as significantly based on professional practice, where knowledge is developed through, and concurrently with, discipline-related performance. Unit $\mathrm{E}$ is a project management unit with all of the assessment related to a progressive, group-based simulation of a project management case study; unit $\mathrm{F}$ is a Chinese language unit based on the interactive development of spoken and written language skills in simulated everyday contexts; and unit $\mathrm{G}$ covers freelancing in the arts with all of the assessment related to class-based performance/participation. While such units would not preclude the wider use of library resources, it is perhaps more likely that the principal learning materials will be a relatively small set of resources whose purpose is to assist students to develop practical skills based on an accepted discipline model and/or the professional experiences of the teacher. In this regard, the learning resources for these units are more likely to be self-contained. Certainly, there is no reference to the discipline-related literature in the handbook outlines for these units. It has been suggested that first- and second-year university language units are likely to have a focus on proficiency in basic vocabulary and grammar, and that opportunities for explicit engagement with the library will be limited (Reznowski, 2008). 
The proposed distinguishing characteristics of the high and low rating units are not mutually exclusive. An apparent strong 'practice' focus in the units with low mean ratings for SETU item 6 does not mean that the high rating units are exclusively theoretical in nature. Overt references to 'literature' in a majority of the unit descriptions of units with high mean ratings for SETU item 6 do not preclude the low rating units from engagement with discipline literature. It is acknowledged that, compared to the relatively objective statistical analysis of the SETU data, the profiling exercise is based on qualitative interpretations of the summary handbook descriptions, and at this point should be taken as more indicative than definitive. In addition, there are other systematic and potentially confounding influences on SETU ratings that need to be considered. While the observed high and low rating unit groupings above did not exhibit any uniformity in year level or discipline area, a previous investigation at Deakin University did find that year level and discipline area were systematic influences on the mean SETU rating for item 6 . It was found that postgraduate units had higher mean ratings than undergraduate units, and units from the health sciences had higher ratings than all others (Palmer, 2012), though the effect sizes were minor.

Likewise, other research has shown that the characteristics of individual teaching staff can have modest effect on SET data (Denson, Loveday \& Dalton, 2010), and over time the staff teaching in a particular unit will naturally change.

\section{Implications for practice}

It has been observed that high ratings of library user service satisfaction may be associated with the active promotion of such services (Mundt, 2003). But, in the case of library resources, merely promoting resources to students is unlikely to lead significant additional use or appreciation of such resources in a unit of study that is not structured to provide students with a rationale for engaging with them. What seems clear is that those units which explicitly incorporate student interaction with information resources beyond those provided within the relatively enclosed unit environment are more likely to lead students to engage with the library in some form. Assessment appears to be an important strategic lever for generating student engagement with the library. Students are strongly (and rationally) motivated by what is assessed (James, McInnis \& Devlin, 2002), and assessment tasks that incorporate opportunities to interact with the library in substantial ways have the potential to result in higher student ratings of the value of library resources. This contention is supported by the observed link in the Deakin University AUSSE data that complex assessment tasks are associated with student use of the library. Changing unit assessment can only be achieved by working with unit chairs/convenors and those with the responsibility of designing the unit learning environment. Convincing busy academic staff of the need to modify their units will require both a strong rationale and ready suggestions for change. Results from analyses based on the profiling method presented here, tactfully presented, may assist in identifying the need for action. Building a collection of cases/exemplars of unit interventions, including the evaluation of effective impacts, may assist in demonstrating the worth of action. The exact form(s) of intervention will depend on the discipline area in question and the nature of the unit under consideration, and will require the professional expertise of the librarian, along with excellent listening, advocacy and negotiation skills. 
The academic staff performance evaluation system at Deakin University incorporates consideration of SETU results. As Figure 3 shows, the mean rating for SETU item 6 is often amongst the lowest of the ten items reported. Anecdotally, a common response from staff to a low rating for item 6 is to suggest that it is "the responsibility of the library". In reality, the strong association between SETU item 6 and all other SETU items observed in Table 1 and Figure 4 suggests otherwise. Whether it is due to a 'halo effect' association with other unit SETU item ratings (good or bad), and/or as a direct and natural consequence of the pedagogy and assessment methods employed in the unit, it would seem that the mean rating obtained for SETU item 6 is significantly the responsibility of those planning and teaching the unit. Achieving any changes desired to improve the mean rating for SETU item 6 is likely to require meaningful discussions with the unit chair/team regarding the learning design employed in the unit. Currently, a 'high' mean rating for all SETU items is viewed as a desirable goal. Given that the mean rating for SETU items 6 seems to be linked at least partially to the nature of, and pedagogy adopted by, the unit in question, the universal desirability of achieving the highest possible rating for SETU item 6 could be reconsidered. Units of study with the specific intention of being performance- or practice-based might not be expected to automatically receive as high a mean rating for SETU item 6 as units specifically designed to engage with discipline-related literature resources.

\section{Conclusion}

Surveys of service quality are widely used in libraries as a measure of user satisfaction. However, student evaluation of teaching (SET) data suggest that even when library service quality is rated highly, library resource quality may not necessarily be. Using large institutional SET data sets containing items related to the library, it was observed that student mean rating of library resources was significantly and positively correlated with the mean ratings of all other aspects of units of study surveyed. This result, by itself, did not usefully illuminate which unit characteristics differentially contributed to student ratings of library resource quality. A new methodology incorporating both quantitative and qualitative profiling was proposed to help discern the unit characteristics that were the differentiators of student ratings of library resource quality. From the sub-set of those units with an 'unremarkable' rating for teaching quality (those around the mean of all mean teaching ratings), those units with the 'extreme' (highest and lowest) library resource quality ratings were selected for investigation.

Examination of the handbook descriptions for those units suggested that units of study which explicitly incorporated student interaction with the wider literature and other information resources beyond those provided within the unit environment may lead students to engage with the library in deeper ways that highlight the value of library resources, and hence lead to higher mean ratings of library resource quality.

The unit selection method documented here provides a process for identifying those units of study with a high or low mean rating of library resource quality relative to their mean rating for general teaching quality. While it would be possible to use the method described in this paper to 'target' specific units for 
'remediation' in relation to low ratings for SETU item 6, such an action is not yet warranted. The profiling of the selected units presented here was a desk audit of publicly available unit descriptions. A more extensive investigation covering the unit learning resources and interviews with the unit chairs might confirm (or refute) the findings and/or reveal other characteristics that might serve as differentiators between those units scoring high and low mean ratings of library resource quality. It is hoped that this initial work will act as a stimulus for additional investigation into those factors that contribute to students valuing library learning resources.

\section{References}

Arambewela, R. \& Hall, J. (2006) A comparative analysis of international education satisfaction using SERVQUAL, Journal of Services Research, 6(1), 141-163.

Barrie, S. \& Ginns, P. (2007) The linking of national teaching performance indicators to improvements in teaching and learning in classrooms, Quality in Higher Education, 13(3), 275-286.

Brookes, M. (2003) Evaluating the 'student experience': An approach to managing and enhancing quality in Higher Education, Journal of Hospitality, Leisure, Sport and Tourism Education, 2(1), 17-26.

Brown, T.J., Churchill Jr, G.A. \& Peter, J.P. (1993) Improving the measurement of service quality, Journal of Retailing, 69(1), 127-139.

Buttle, F. (1996) SERVQUAL: review, critique, research agenda, European Journal of Marketing, 30(1), 8-32.

Chen, I.J., Gupta, A. \& Rom, W. (1994) A study of price and quality in service operations, International Journal of Service Industry Management, 5(2), 23-33.

Coates, H. (2010) Development of the Australasian survey of student engagement (AUSSE), Higher Education, 60(1), 1-17.

Cook, C., Heath, F., Kyrillidou, M. \& Webster, D. (2001) The forging of consensus: a methodological approach to service quality assessment in research libraries - the LibQUAL+TM experience, in: 4th Northumbria International Conference, Pittsburgh, PA, 93-103.

Crawford, J. (2003) Reviewing a programme of evaluation in an academic library: the case of Glasgow Caledonian University, Performance Measurement and Metrics, 4(3), 113-121.

Deakin University (2009) Teaching and Learning Committee Agenda Paper 15.1

- Recommendation for changes to the SETU questionnaire for 2010. URL: http://theguide.deakin.edu.au/TheGuide/TheGuide2011.nsf/e216f1c834e829d2ca2 57735000b9a44/c58970e566ab4697ca25778b0008afe8/\$FILE/ATTCCJ16.pdf/A genda\%20Paper\%2015.1.pdf\#page $=13$ [accessed 5 June 2012]. 
Deakin University (2010) Handbook archive. URL:

http://www.deakin.edu.au/current-students/handbooks/2010/archive.php [accessed 5 June 2012].

Deakin University (2011) Unit Evaluation System. URL: http://www.deakin.edu.au/unit-eval/results/general.php [accessed 5 June 2012].

Denson, N., Loveday, T. \& Dalton, H. (2010) Student evaluation of courses: what predicts satisfaction?, Higher Education Research \& Development, 29(4), 339 356.

Graduate Careers Australia (2010) Graduate Course Experience 2009 - The report of the course experience questionnaire. Melbourne: Graduate Careers Australia.

Griffiths, J.R. (2008) Measuring the quality of academic library electronic services and resources, in: 17th Hellenic Conference of Academic Libraries, Ioannina, 1-14.

Gruber, T. \& Voss, R. (2010) Examining student satisfaction with higher education services, The International Journal of Public Sector Management, 23(2), 105-123.

Horn, A., Calvert, P. \& Ferguson, S. (2009) Academic libraries. In: Abdullahi, I. (ed.), IFLA Publications 136-37: Global Library and Information Science. The Hague: International Federation of Library Associations and Institutions. 243-252.

James, R., McInnis, C. \& Devlin, M. (2002) Assessing Learning in Australian Universities. Melbourne: Centre for the Study of Higher Education and The Australian Universities Teaching Committee.

Jayasundara, C.C. (2011) A modular approach to customer satisfaction in relation to service quality, Journal of the University Librarians' Association of Sri Lanka, 15(1), 23-82.

Joo, S. (2010) Effects of ease of use, effectiveness, and use frequency on user satisfaction in academic library website uses, in: iConference 2010 Proceedings, Urbana-Champaign, 454-456.

Li, R.Y. \& Kaye, M. (1998) A Case Study for Comparing Two Service Quality Measurement Approaches in the Context of Teaching in Higher Education, Quality in Higher Education, 4(2), 103-113.

Mundt, S. (2003) Benchmarking user satisfaction in academic libraries - a case study, Library and Information Research 27(87), 29-37.

Nitecki, D.A. (1996) Changing the concept and measure of service quality in academic libraries, The Journal of Academic Librarianship, 22(3), 181-190.

Owusu-Ansah, E.K. (2004) Information Literacy and Higher Education: Placing the academic library in the center of a comprehensive solution, The Journal of Academic Librarianship, 30(1), 3-16.

Palmer, S. (2012) Discovering the value that the library can contribute to quality teaching and learning through student evaluation data, in: Australian Library and Information Association Biennial Conference 2012, Sydney. 
Parasuraman, A., Zeithaml, V.A. \& Berry, L.L. (1988) SERVQUAL: A multipleitem scale for measuring consumer perceptions of service quality, Journal of Retailing, 64(1), 5-6.

Pike, G.R. (1999) The constant error of the halo in educational outcomes research, Research in Higher Education, 40(1), 61-86.

Reznowski, G. (2008) The librarian's role in motivating language learners: Tales from an Eastern Washington college town, Reference Services Review, 36(4), 414423.

Rooney-Browne, C. (2011) Methods for demonstrating the value of public libraries in the UK: A literature review, Library and Information Research 35(109), 3-39.

Symons, R. (2004) Getting the most out of the SCEQ data: meeting the needs of multiple stakeholders, in: 2004 Evaluation Forum, Melbourne, 12-22.

Thompson, B., Cook, C. \& Kyrillidou, M. (2006) Using localized survey items to augment standardized benchmarking measures: A LibQUAL+TM study, portal: Libraries and the Academy, 6(2), 219-230.

Walters, W.H. (2003) Expertise and evidence in the assessment of library service quality, Performance Measurement and Metrics, 4(3), 98-102.

West, C. (2001) Measuring User Satisfaction: A Practical Guide for Academic Libraries. London: Society of College, National and University Libraries.

Zauha, J. \& Potter, G. (2009) Out west and down under, Library Management, 30(8/9), 549-560.

\section{Open access and copyright}

Library and Information Research is an open access journal. A freely available copy of this paper may be downloaded from the journal's website: http://www.cilipjournals.org.uk/lir

Copyright and associated moral rights in works published in Library and Information Research are retained by the author(s) but this paper may be used freely, with proper attribution, in educational and other non-commercial settings. 